\title{
Disperse systems temperature field finding at reception of firm crystal-amorphous structures
}

\author{
Y.V. Kornienko, P.M. Magaziy, K.O. Gatilov, R.V. Sachok \\ National Technical University of Ukraine "Igor Sikorsky Kyiv Polytechnic Institute”, \\ str. Polytechnichna, 39, Bldg. 19, Kyiv, 03056, Ukraine \\ Tel.: +380444068451 \\ E-mail:ynk@kpi.ua
}

Article info: received 13.11.2018, revised 18.11.2018, accepted 26.11.2018

Kornienko, Y.V., Magaziy, P.M., Gatilov, K.O., Sachok, R.V. (2018) Disperse systems temperature field finding at reception of firm crystal-amorphous structures 4(41), doi: 10.26909/csl.4.2018.2.

The temperature field of firm crystal-amorphous structures receiption from liquid systems in the fluid bed is explored. The stable conducting terms of process are certain.

Previous studies have shown that increasing the irrigation density increases the probability of formation of agglomerates, which causes a decrease in temperature; therefore, it is advisable to measure the temperature field in the environment of the dispersant and compare it with the values of temperatures at the characteristic point, according to which the regulation of the flow of liquid phase to the granulator is carried out.

The objective of the experimental research was to determine the change of the temperature field in disperse systems in obtaining crystalline-amorphous solid structures in a fluidized-bed apparatus.

In case of an increase in the amount of heat flow, an adequate increase in the flow of liquid phase occurs. This results in the local overturning of solid particles and, as a result, the formation of large aggregates and loss of quality of fluidization. To eliminate this disadvantage it is advisable to create conditions for uneven distribution of the coolant speed.

In the downstream right and left fluxes, the coolant speed should not exceed the rate of gas filtration through the material. In the left upward flow, in which the direction of motion of the granular material is opposite to the direction of the vector of the linear velocity of the dispersed droplets of the liquid phase, it is expedient to increase the flow of the coolant in a direction that coincides with the downstream flow. To verify these provisions, it is expedient to conduct a study of the continuous process of formation of solid multilayer composites.

Key words: crystal-amorphous structures, disperse systems.

\section{Визначення температурного поля в дисперсних системах при одержанні кристалічно-аморфних твердих структур}

\author{
Я.М. Корнієнко, П.М. Магазій, К.О. Гатілов, Р.В. Сачок \\ Національний технічний університет України “Київський політехнічний інститут”, Київ, Украӥна
}

Досліджено температурне поле при одержанні кристалічно-аморфних твердих структур з рідких систем у псевдозрідженому шарі. Визначено температурне поле в зоні гранулювання рідкої фази при стійкій кінетиці гранулоутворення.

Попередніми дослідженнями встановлено, що підвищення щільності зрошення збільшує вірогідність утворення агломератів, що спричиняє зниження температури, тому доцільно провести вимірювання температурного поля в довкіллі диспергатора і порівняти із значеннями температур в характеристичній точці, за показаннями якої проводиться регулювання витрат рідкої фази до гранулятора. 


\section{Умовні скорочення та познаки}

$a_{f}$ - питома щільність зрошення поверхні частинок, кг/(м².год); $D_{\text {е }}$ - еквівалентний діаметр частинок, мм; $K_{w}$ - число псевдозрідження; $t$ - час, с; $T_{\text {вх }}$ - температура на вході в псевдозріджений шар, ${ }^{\circ} \mathrm{C} ; T_{\text {ш }}-$ температура в псевдозрідженому шарі, ${ }^{\circ} \mathrm{C} ; W_{\mathrm{p}}$ - робоча швидкість псевдозрідження; $x_{1}-$ відстань від бічної стінки до першої термопари, мм; $x_{2}$ - відстань від бічної стінки до другої термопари, мм; $x_{3}-$ відстань від бічної стінки до третьої термопари, мм; $x_{4}-$ відстань від бічної стінки до четвертої термопари, мм; $x_{\text {ш }}$ відстань від бічної стінки до термопари в характеристичній точці, мм; $\Delta P_{\text {ш }}$ - перепад тиску на шарі, Па; $\Delta T$ - середня корисна різниця температур, ${ }^{\circ} \mathrm{C} ; \psi$ - коефіцієнт гранулоутворення; ПК - персональний комп’ютер.

\section{Вступ}

Застосування техніки псевдозрідження для зневоднення та сушіння багатофазних дисперсних рідких систем, що містять мінеральні й органічні речовини, дозволяє одержувати багатошарові капілярно-пористі тверді композити 3 рівномірним розподіленням компонентів по всьому об'єму [1].

Комплексні кристалічно-аморфні тверді структури розглядались на прикладі мінерально-гумінових твердих композитів. Готовим продуктом $\epsilon$ сферичні гранули розміром 1,5 - 4,5 мм з рівномірним розподіленням компонентів по всьому об'єму на нанорівні та міцністю більше 10 Н на гранулу. Застосування цих композитів в якості добрив дозволить зберегти грунти та сприятиме впровадженню принципів сталого розвитку в Україні.

В композитах такого складу при високих температурах відбувається вилучення летких компонентів 3 мінеральних речовин та деструкція органічних компонентів, що зумовлює створення відповідного гідродинамічного режиму.

В залежності від способу введення рідкої фази i наявності вертикальної направленої циркуляції зернистого матеріалу в псевдозрідженому шарі [2], може здійснюватись два механізми гранулоутворення: багатошарових капілярно-пористих структур за рахунок багатократної масової кристалізації мінеральних компонентів; твердих структур за рахунок агломерації дрібних частинок.

Останній механізм є небажаним, оскільки не дозволяє забезпечити рівномірне розподілення компонентів по всьому об'єму композиту і призводить до непередбачуваної зміни дисперсного складу частинок та до розбалансування процесу.

Попередніми дослідженнями встановлено, що підвищення щільності зрошення збільшує вірогідність утворення агломератів, що спричиняє зниження температури, тому доцільно провести вимірювання температурного поля в довкіллі диспергатора і порівняти із значеннями температур в характеристичній точці, за показаннями якої проводиться регулювання витрат рідкої фази до гранулятора.

\section{Матеріали та методи дослідження}

Задачею експериментальних досліджень було визначення зміни температурного поля в дисперсних системах при одержанні кристалічно-аморфних твердих структур в апараті з псевдозрідженим шаром.

Вимірювання температурного поля проводилось при безперервному процесі зневоднення та сушіння органо-мінеральних багатошарових гуміново-азотно-калійних твердих композитів складу $\left(\mathrm{NH}_{4}\right)_{2} \mathrm{SO}_{4}: \mathrm{K}_{2} \mathrm{SO}_{4}$ : гумати: $\mathrm{H}_{2} \mathrm{O}=71,74: 27,16: 1,00: 0,10$ за допомогою блоку термопар. Диспергування рідкої фази проводилось конічним диспергатором. Схема апарату приведено на рис. 1 .

Температура теплоносія в характеристичній точці псевдозрідженого шару 5 разом $з$ температурами, які вимірювались дослідним зондом та фіксувались комп'ютерним комплексом, що складається 3 модулів збору даних I-7018 з перетворювачем-інтерфейсом RS-232 (I-7520). Цифровий сигнал із інтерфейсу поступає в комп'ютер, де використовується середовище графічного програмування для збору, обробки даних та їх візуалізації - Laboratory Nirtual Instrument Engineering Workbench - LabVIEW. Базова версія Base Package інструментального середовища має особливі засоби програмування і візуалізації компонентів обміну по мережам RS-232/485. Обробка результатів виміру з урахуванням тарувальних функцій, а також графічні залежності виконані в середовищі Microsoft Office Excel. Сигнал з регулюючої термопари, розташованої в характеристичній точці подавався також на сьомий канал АЦП, для порівняння $з$ температурами виміряними дослідним шляхом.

\section{Результати та їх обговорення}

Результати наведені на рис. 2 - 5 .

На рис. 2 наведена динаміка зміни температурного поля у правому низхідному потоці II (рис. 1). При цьому $D_{\mathrm{e}}=2,3 \mathrm{мм}, K_{w}=1,8\left(W_{\mathrm{p}}=0,85 \mathrm{~m} / \mathrm{c}\right)$, $\Delta P_{\mathrm{m}}=2100$ Па, $\psi=94,34 \%, \mathrm{i} a_{f}=0,251$ кг вол/(м ${ }^{2}$ год).

Протягом 40 с проходив нагрів зонду, після чого проводилося вимірювання температур. Спеціальний 


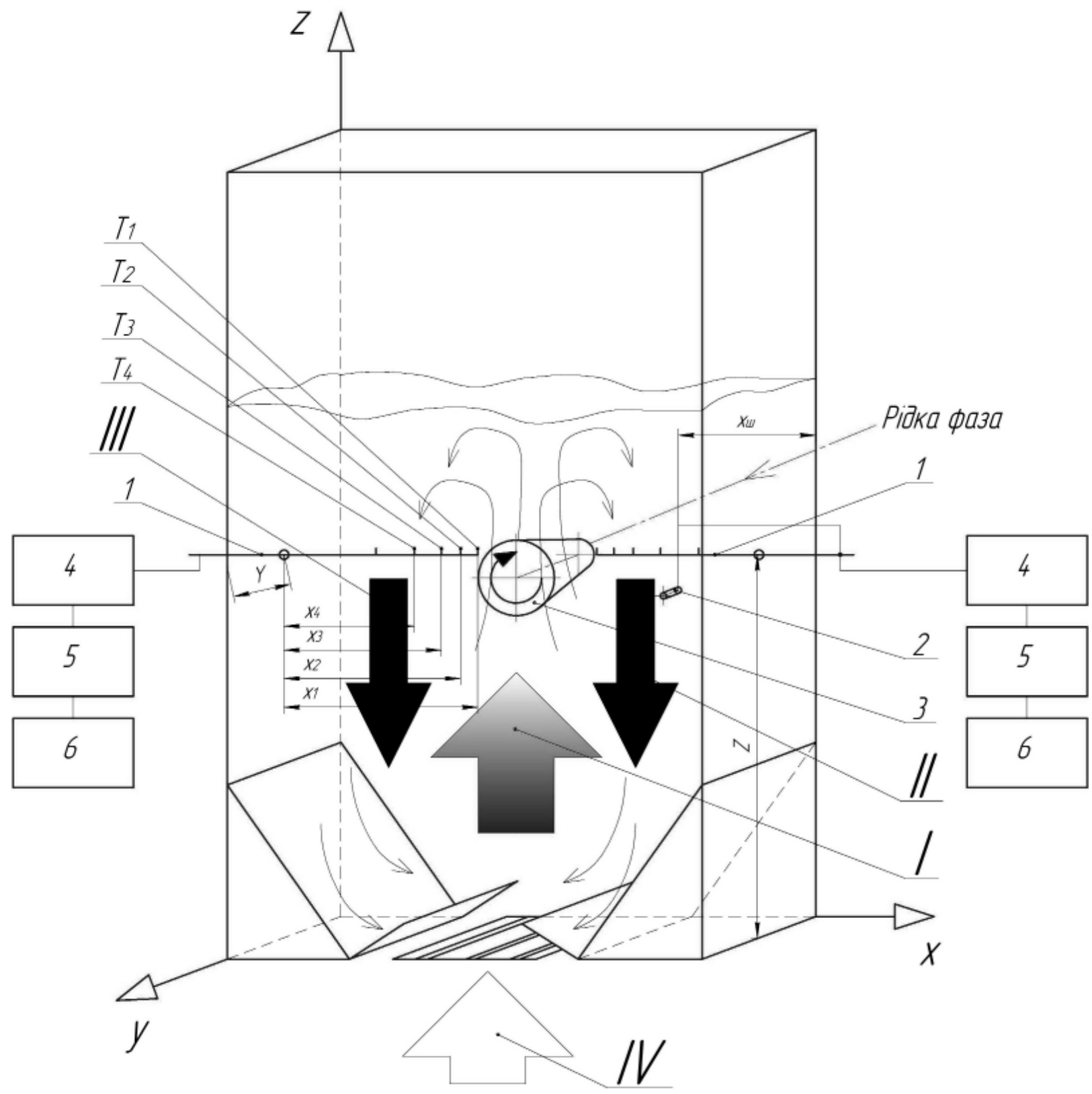

Рис. 1. Схеми вимірювання температурного поля в зоні диспергатора:

1 - зонд вимірювальних термопар; 2 - термопара в характеристичній точці; 3 - барабанний диспергатор; 4 - модуль збору даних;

5 - інтерфейс; 6 - ПК; $T_{1}, T_{2}, T_{3}, T_{4}$ - відповідно 1-ша $\left(x_{1}=133\right.$ мм), 2-га $\left(x_{2}=118\right.$ мм) 3-тя $\left(3-x_{3}=93\right.$ мм) та 4-та $\left(x_{4}=58\right.$ мм $)$ термопари; $I$ - висхідний потік зернистого матеріалу;

II - правий низхідний потік зернистого матеріалу; III - лівий низхідний потік зернистого матеріалу; $I V$ - нагрітий теплоносій 


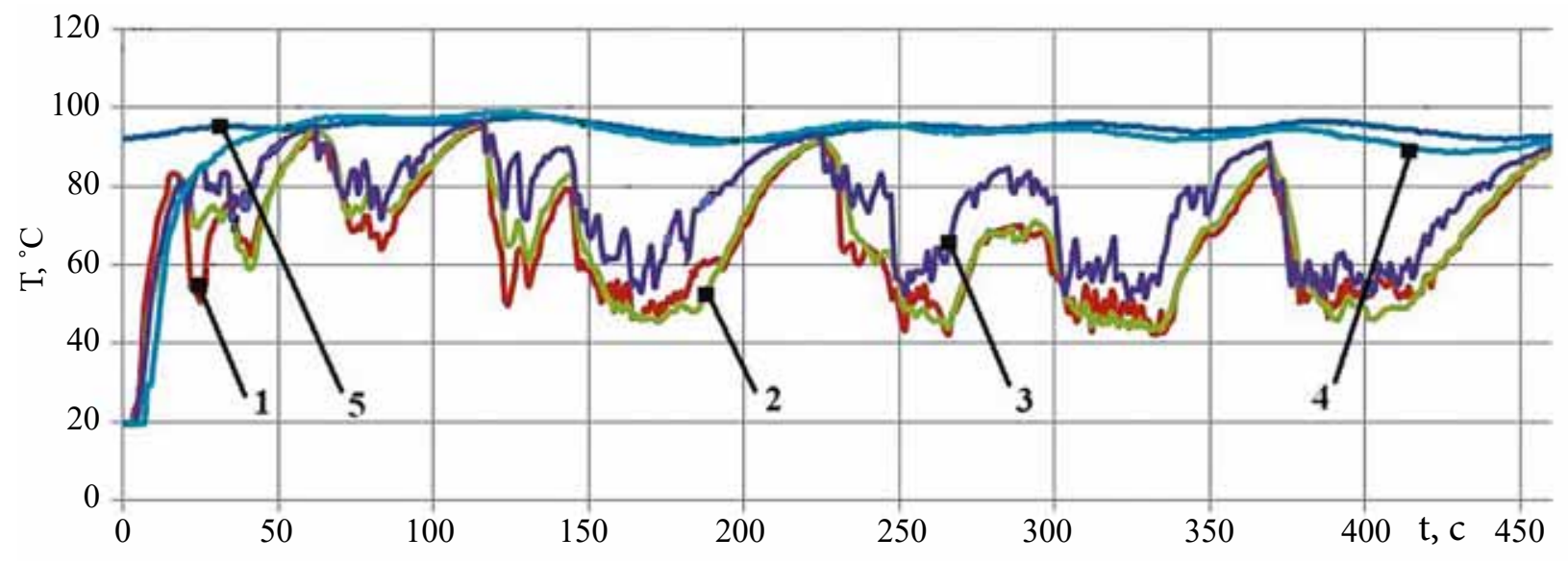

Рис. 2. Динаміка зміни температур в правому низхідному потоці $I I$ : $1-x_{1}=133 \mathrm{мм} ; 2-x_{2}=118 \mathrm{мм} ; 3-x_{3}=93 \mathrm{мM} ; 4-x_{4}=58 \mathrm{мм} ; 5-x_{\mathrm{uI}}=70 \mathrm{мм}$

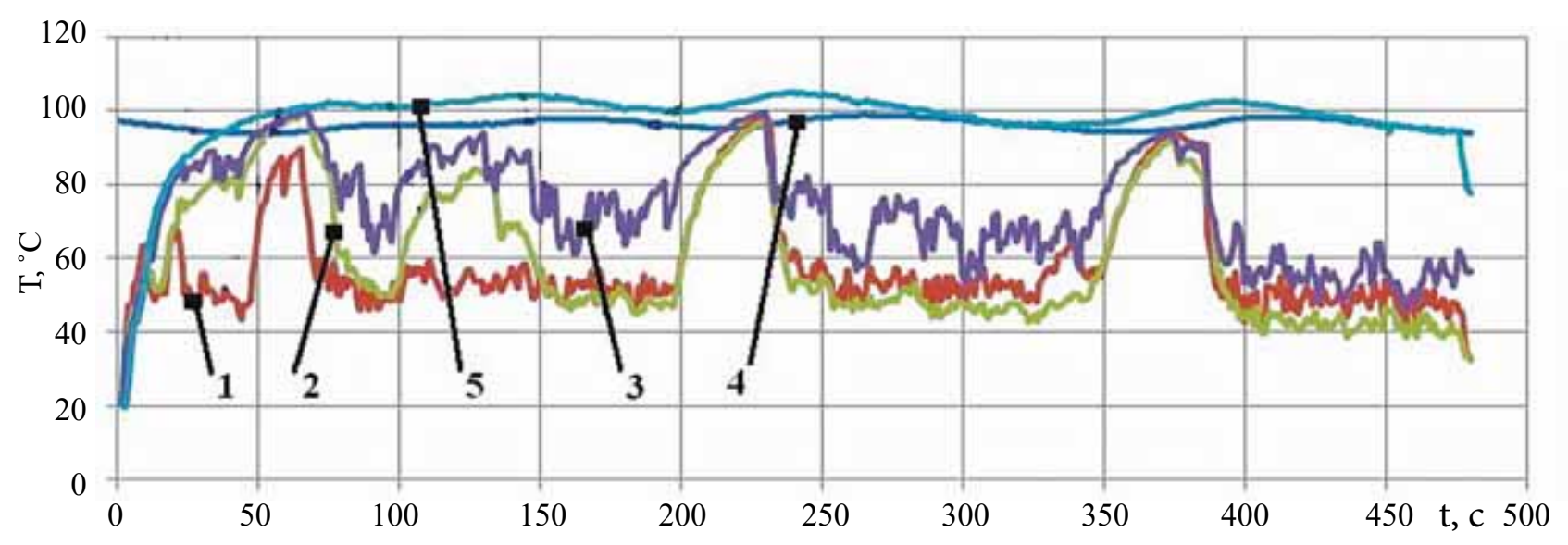

Рис. 3. Динаміка зміни температур у лівому низхідному потоці III: $1-x_{1}=133 \mathrm{мм} ; 2-x_{2}=118 \mathrm{мм} ; 3-x_{4}=93 \mathrm{мм} ; 4-x_{6}=58 \mathrm{мм} ; 5-x_{\mathrm{m}}=70 \mathrm{мм}$

зонд термопар розміщався на однаковій висоті з віссю обертання диспергатора. Температура, виміряна в точках 1 i 2, які є найближчими точками до диспергатора, у проміжку часу $80 \ldots 95$ с мали відповідні максимальні зниження температури. Це свідчить про те, що в цих точках до системи зернистий матеріал-газовий теплоносій додається ще рідка фаза у вигляді дрібних крапель з нерівномірним спектром диспергування і недостатнє перемішування в цій зоні. При віддалені від осі обертання диспергатора, в точці 4 температура зменшувалась не так стрімко. Такий характер зміни температури свідчить про інтенсивне перемішування. Зміни температури по горизонтальній осі в різні періоди часу для точок 1,2 була в межах $88-97{ }^{\circ} \mathrm{C}$. При цьому значення температури в точки 5 досягалось $98^{\circ} \mathrm{C}$. Це пояснюється тим, що за рахунок інтенсивного перемішування відбувається перерозподі- лення рідкої фази з одночасним випаровуванням розчинника.

Після 230 с і до 247 с починається подача рідкої фази і спостерігається зменшення температури у всіх точках. Після 268 с подача розчину припиняється і температура починає підвищуватись у всіх точках.

На рис. 3 наведена динаміка зміни температурного поля у лівій області диспергатора. При цьому $D_{\mathrm{e}}=2,3 \mathrm{мM}, K_{w}=1,8\left(W_{\mathrm{p}}=0,86 \mathrm{M} / \mathrm{c}\right), \Delta P_{\mathrm{II}}=2200 \Pi$ П, $\psi=92,24 \%$, i $a_{f}=0,267$ кг $/\left(\mathrm{M}^{2}\right.$ ггод).

Протягом 40 сек. проходив нагрів зонду, після чого проводилося вимірювання температур. В період прогріву термопар, $t \leq 40 \mathrm{c}$, точка 1 потрапила в зону зрошення i їх температура суттєво впала, а температура в точках 2, 3 і 4 продовжувала зростати. 3 цього можна зробити висновок що зрошення зернистого шару відбувається на відстані 50 мм від 


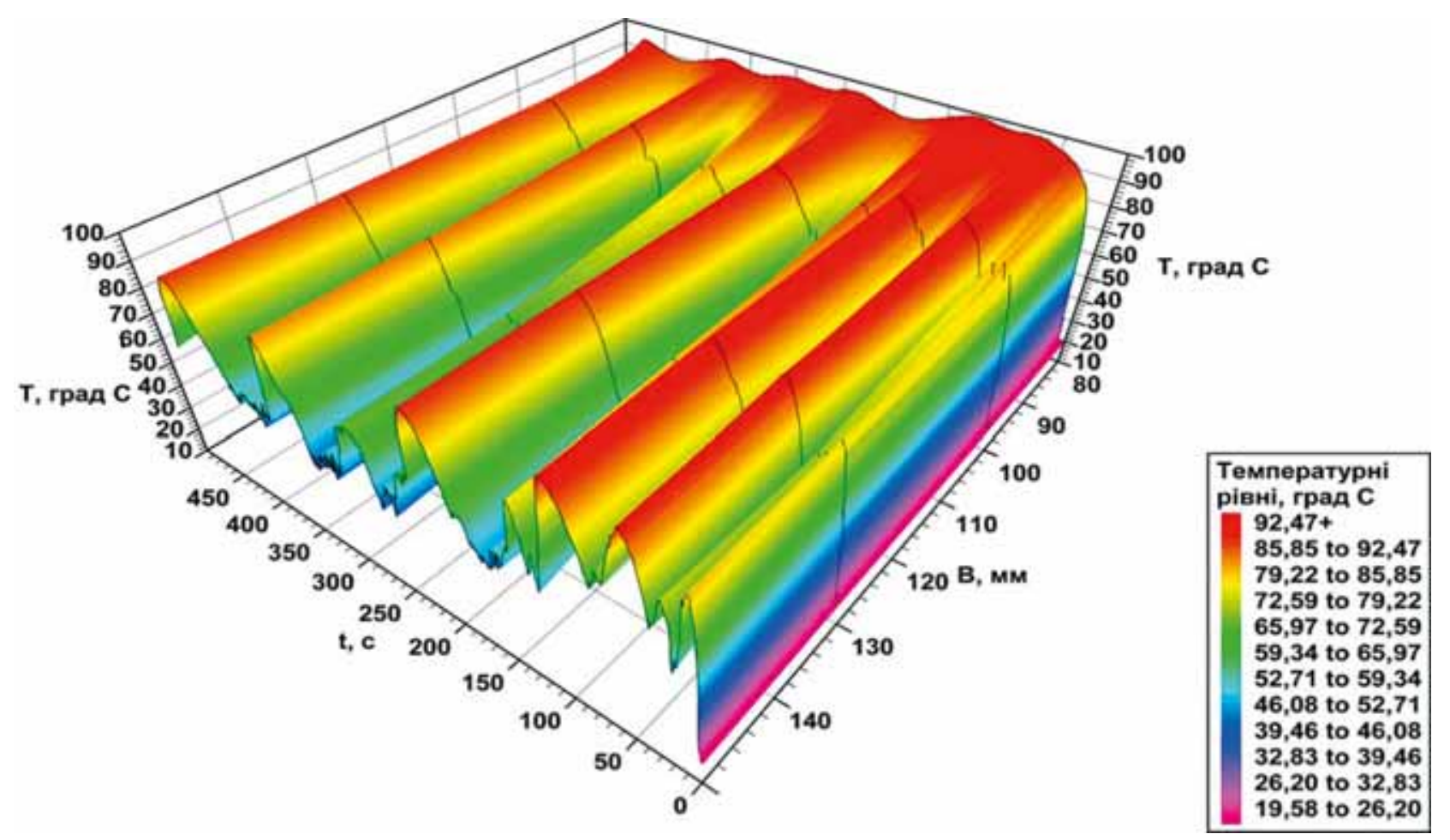

Рис. 4. Поле температур у правому низхідному потоці II

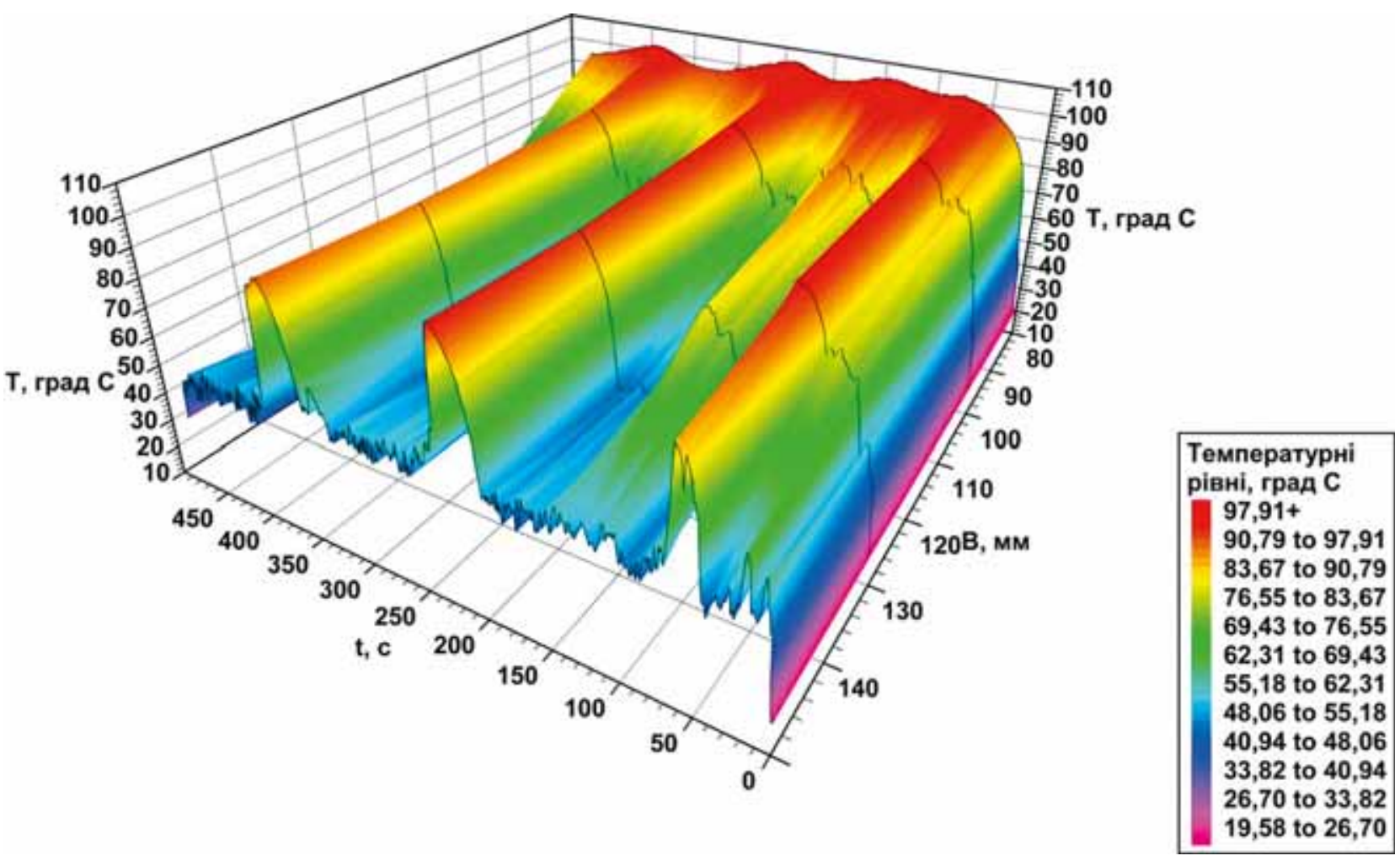

Рис. 5. Поле температур у лівому низхідному потоці III 
осі диспергатора. Протягом всього часу вимірювання температури в точках 1, 2 і 3 змінювались 3 великою частотою та амплітудою, в 4-й точці зміна температури відбувається більш плавно.

3 рис. 3 видно, що на 62 с та 127 с відбувалась подача розчину і температура в точках 1,2 та 3 зменшилась, а в точці 4 була майже однаковою. Це свідчить про те, що при даних значеннях $K_{w}=1,8$ вирівнювання температури в зоні диспергатора відбувається на відстані 50 - 90 мм від осі, або 20 - 60 мм від робочої поверхні диспергатора, тобто на цій відстані спостерігається рівномірне перемішування та перерозподіл вологи в зернистому матеріалі.

Більш повну динаміку зміни температурних полів в правому та лівому низхідних потоках наведені на рис. 4 та 5 відповідно. Горизонтальна вісь часу діаграм співпадає з горизонтальною віссю обертання диспергатора.

Динаміки зміни температур в лівому та правому низхідному потоці (рисунок 4 та 5) мають пульсуючий характер, проте в лівому низхідному потоці є довготривалі ділянки зниження температур (150 - 250 с та 300 - 400 с), що свідчить про надмірне зволоження зернистого матеріалу. Приведений час протікання для кожної 3 цих двох ділянок (відношення реального часу наявності низької температури до часу проведення виміру) становить $100 / 500=0,2$. Сумарний приведений час знижених температур в цій зоні більше 0,5, тобто відбувається довготривале перезволоження зернистого матеріалу, що підвищує вірогідність агломерації частинок малого розміру та погіршує кінетику протікання пошарового росту гранул.

\section{Висновки}

Порівняння полів температур в низхідних потоках $з$ правої і лівої сторін, рис. 4 і 5, можна зробити висновок, що при $\Delta T=100{ }^{\circ} \mathrm{C}$ перепад температур в шарі становить близько $50{ }^{\circ} \mathrm{C}$, або $0,5 T_{\text {ш }}$ В подальшому доцільно визначити спосіб виміру температури за показами якої буде проводитись регулювання подачі рідкої фази.
Загальний вигляд динаміки температурного поля наведений на рис. 5 свідчить про існування імпульсного режиму рідкої фази при різниці між максимальним і мінімальним значеннями більше $40{ }^{\circ} \mathrm{C}$. Враховуючи, що процес реалізувався при $\Delta T=T_{\mathrm{вx}}-T_{\mathrm{m}}=100 \pm 5^{\circ} \mathrm{C}$, що є мінімальною для апаратів даного типу, в разі збільшення величини теплового потоку відбувається адекватнезбільшення витрат рідкої фази. Це призводе до локального перезволоження твердих частинок $\mathrm{i}$, як результат, утворення великих агрегатів і втраті якості псевдозрідження. Для усунення цього недоліку доцільно створити умови нерівномірного розподілу швидкості теплоносія.

В зоні диспергуванням рідкої фази швидкість теплоносія має дорівнювати швидкості виносу частинок розміром $D_{\text {e }}$ (висхідна зона). Це дозволить зменшити час перебування твердих частинок в зоні зрошення та підвищити рушійну силу масообміну. В низхідних правому та лівому потоках швидкість теплоносія не повинна перевищувати швидкості фільтрації газу через матеріал. В лівому висхідному потоці, в якому напрямок руху зернистого матеріалу протилежний напрямку вектора лінійної швидкості дисперсних крапель рідкої фази, доцільно збільшити витрати теплоносія в напрямку, що співпадає 3 низхідним потоком. Для перевірки цих положень доцільно провести дослідження безперервного процесу утворення твердих багатошарових композитів.

\section{References}

1. Патент №4465 Україна, МПК C05 G1/00. Спосіб виготовлення гранулоутворених ограномінеральних добрив / Я.М. Заграй, Я.М. Корнієнко. - (Україна). - №93121640; заявл. 21.05.93; опубл. 27.12.94, бюл. № 6-1. -4 c.

2. Корнієнко, Я.М., Гатілов, К.О. Гідродинаміка псевдозрідженого шару в процесі одержання багатошарових твердих композитів із заданими властивостями // Одеська національна академія харчових технологій, Наукові праці випуск №35, том 2. Одеса. - 2009. - С. 62 - 66. 